nGROzcossistemns

Núcleo de Meio Ambiente Universidade Federal do Pará Rua Augusto Corrêa, 01, Guamá Belém, Pará, Brasil https://periodicos.ufpa.br/index.php/agroecossistemas

Paulo César Machado Andrade Universidade Federal do Amazonas pcmandra@yahoo.com.br

Vanessa Souza Altino Universidade Estadual de Santa Cruz van.altino@gmail.com

Natasha Nascimento Tuma Universidade Federal do Amazonas natashatuma@gmail.com

\begin{abstract}
Karen Patrícia Melo Martins Universidade Federal do Amazonas martinskaren@gmail.com
\end{abstract}

Elias Santos da Costa Instituto Federal do Amazonas eliasandacos@gmail.com

Recebido em: 2020-08-07 Avaliado em: 2020-08-10 Aceito em: 2020-09-04

\section{UTILIZAÇÃO DE SUBPRODUTOS REGIONAIS NA ALIMENTAÇÃO DE CAITETUS (Pecari tajacu) EM CATIVEIRO NA AMAZÔNIA CENTRAL}

RESUMO: A carne de caitetu (Pecari tajacu) é muito apreciada na Amazônia. Este estudo objetivou avaliar níveis de subprodutos regionais (casca e torta de caroço de cupuaçu, Theobroma grandiflorum; torta do caroço de tucumã, Astrocaryum aculeatum; torta do caroço de muru-muru, Astrocaryum murumuru) em substituição ao milho em rações para alimentação de caitetus em cativeiro. Em quatro períodos experimentais, foram avaliados 45 animais (10 machos e 35 fêmeas, pesando $11,7 \pm 5,8$ e 13,7 $\pm 4,8 \mathrm{~kg}$, respectivamente), sendo alojados 12 animais/período em quatro baias de $15 \mathrm{~m} 2$, que receberam quatro tratamentos (T0 = ração controle; T10 = ração com 10\% do subproduto substituindo o milho; T20 = ração com 20\% de substituição; T30 =ração com 30\% de substituição). Animais que receberam até $10 \%$ de casca de cupuaçu tiveram maior peso, 19,2 $\pm 1 \mathrm{~kg}(\mathrm{P}<0,0001)$. Caitetus alimentados com ração de $10 \%$ de torta de cupuaçu foram mais pesados ( $23 \pm 1,7 \mathrm{~kg}$; $\mathrm{P}<0,01)$ do que os de $50 \%$ (13 $\pm 0,5 \mathrm{~kg})$, e tiveram maior ganho em peso (59 $\pm 33 \mathrm{~g} /$ dia; $\mathrm{P}<0,02)$. Com torta de caroço de tucumã, os animais com maior peso foram do tratamento com nível de $20 \%$ (24 $\pm 1,7 \mathrm{~kg})$, mas os animais que tiveram melhor conversão $(7 \pm 6,6)$ foram de $30 \%$ de substituição. Com a torta do muru-muru (A. murumuru), os animais que receberam ração com $9 \%$ de subproduto apresentaram o maior peso $(13,3 \pm 1,5 \mathrm{~kg} ; \mathrm{P}<0,001)$ e o com 15\% de substituição apresentaram o maior ganho diário em peso $(74,1 \pm 5,7 \mathrm{~g} /$ dia; $\mathrm{P}<0,01)$.

PALAVRAS-CHAVE: Astrocaryum, co-produtos, Theobroma. 
ABSTRACT: The meat of collared peccary (Tayassu tajacu) is greatly appreciated in the Brazilian Amazonas. Therefore, the objective of this work was to evaluate regional levels of by-products (hull and meal of cupuaçu, Theobroma grandiflorum; meal lump of tucumã; Astrocaryum aculeatum; meal lump of muru muru, Astrocaryum murumuru) replacing corn in the feedeing of peccary in captivity. We used four pens of $15 \mathrm{~m} 2$ in Manaus, where they were housed 12 animals $(13.1 \pm 3.5 \mathrm{~kg})$ who received four treatments ( $\mathrm{TO}=$ control diet; $\mathrm{T} 10=$ diet with $10 \%$ replacement of corn byproduct; $\mathrm{T} 20=$ diet with 20\% replacement; $\mathrm{T} 30=$ diet with 30\% replacement). Animals that received up to $10 \%$ of cupuaçu hull had greater weight, $19.2 \pm 1 \mathrm{~kg}(P<0.0001)$. Peccaries fed with $10 \%$ cupuaçu meal were heavier $(23 \pm 1.7 \mathrm{~kg}, \mathrm{P}<0.01)$ than the $50 \%$ $(13 \pm 0.5 \mathrm{~kg})$ and had greater daily gain weight $(59 \pm 33 \mathrm{~g} /$ day; $P<0.02)$. With meal lump of tucumã, animals were heavier treatment with level $20 \%(24 \pm 1.7 \mathrm{~kg})$, but animals that had the best conversion ( $7 \pm 6.6$ ) were of level $30 \%$. With the meal lump of muru muru (A. murumuru), treatment with $9 \%$ substitution showed the greatest weight $(13.3 \pm 1.5 \mathrm{~kg} ; \mathrm{P}<0.001)$ and with $15 \%$ substitution showed the biggest daily gain weight $(74.1 \pm 5.7 \mathrm{~g} /$ day; $\mathrm{P}<0.01)$.

KEYWORDS: Astrocaryum, by-products, Theobroma.

\section{UTILIZACIÓN DE SUBPRODUCTOS REGIONALES EN LA ALIMENTACÍON DE PECARIES (Pecari tajacu) EN CAUTIVERIO EN LA AMAZONÍA CENTRAL}

RESUMEN: La carne de pecarie (Pecari tajacu) es muy apreciada en la Amazonía. Este estudio tuvo como objetivo evaluar los niveles de subproductos regionales (cáscara y pastel de semilla de cupuaçu, Theobroma grandiflorum; semilla de palma tucumã, Astrocaryum aculeatum; semilla de palma murumuru, Astrocaryum murumuru) como un sustituto del maíz en los piensos de pecaries. en cautiverio En cuatro períodos experimentales, se evaluaron 45 animales (10 machos y 35 hembras, con un peso de $11.7 \pm 5.8$ y $13.7 \pm 4.8 \mathrm{~kg}$, respectivamente). Dos animales / período fueron alojados en cuatro bahías de $15 \mathrm{~m} 2$. quienes recibieron cuatro tratamientos ( $\mathrm{TO}=$ alimento de control; $\mathrm{T} 10=$ alimento con $10 \%$ de sustitución de maíz por subproducto; T20= alimento con 20\% de sustitución; T30 = alimento con 30\% de sustitución). Los animales que recibieron hasta el 10\% de la cáscara de cupuaçu tuvieron mayor peso, $19.2 \pm 1 \mathrm{~kg}$ $(\mathrm{P}<0.0001)$. Pecaries alimentados con un $10 \%$ de ración de semilla de cupuaçu era más pesado $(23 \pm 1.7 \mathrm{~kg} ; \mathrm{P}<0.01)$ que los del $50 \%(13 \pm 0.5 \mathrm{~kg})$, y tenía un mayor aumento de peso ( $59 \pm 33 \mathrm{~g} /$ día; $P<0.02)$. Con el pastel de semilla de tucumã, los animales con el mayor peso fueron tratados con un $20 \%$ de sustitución $(24 \pm 1.7 \mathrm{~kg}$ ), pero los

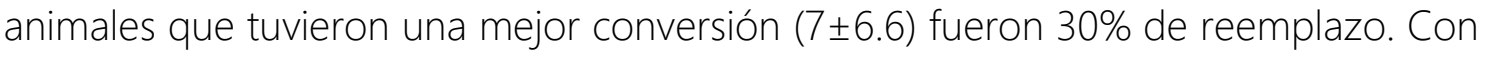
la semilla de muru-muru (A. murumuru), los animales que recibieron una ración de 
sustitución del 9\% presentaron el mayor peso $(13.3 \pm 1.5 \mathrm{~kg}$; $\mathrm{P}<0.001)$ y la ración de sustitución del 15\% presentó el incremento diario de peso más alto $(74.1 \pm 5.7$ g/día; $P<0.01)$.

PALABRAS CLAVES: Astrocaryum, coproductos, Theobroma.

\section{INTRODUÇÃO}

Na Amazônia, a carne de animais silvestres sempre foi uma das fontes protéicas alternativas ao pescado (CANTO et al., 1999) e o comércio do couro foi importante ítem da economia até meados do século $X X$, sendo estimado o abate de mais de 5 milhões de caititus, Pecari tajacu, entre 19041969 (Antunes et al., 2017). Caitetus (Pecari tajacu), ainda são vendidos, ilegalmente em Manaus a $U \$ 4,5 / \mathrm{kg}$, representando $\quad 16 \%$ da caça apreendida e o $4^{\circ}$ lugar na preferência das carnes silvestres (CANTO et al., 1999). Estudos para domesticação desta espécie, vem sendo conduzidos no Brasil e em outros países da América do Sul e Central (ALBUQUERQUE et al., 2016; NOGUEIRA; NOGUEIRA-FILHO, 2011). Embora o caitetu apresente bom potencial zootécnico, os custos com sua alimentação em cativeiro são elevados, representando até 80\%
(SANTOS et al., 2009) ou mais dos custos variáveis, a medida em que se aumenta o plantel, tanto em sistemas semi-intensivos como nas criações intensivas na Amazônia (SOUZA, 2013). Caitetus tem capacidade para digerir bem alimentos com elevados níveis de volumoso (NOGUEIRA-FILHO, 2005), sendo possível testar subprodutos locais altamente fibrosos como folhas de macaxeira, de maracujá e até coroas de abacaxi e talos de bananeira, sem afetar sua digestibilidade (NOGUEIRAFILHO et al., 2006). Além disso, caitetus requerem níveis relativamente baixos de proteína e tem grande habilidade para digerir proteína, sendo possível utilizar baixos níveis de proteína bruta em sua dieta, reduzindo os custos das rações (BORGES et al., 2017).

Albuquerque et al., 2007, avaliou a composição bromatológica de frutos, flores e sementes que servem de alimento para os caititus nas florestas 
de terra firme na Amazônia, para tentar elaborar uma dieta balanceada, sendo que entre os produtos analisados, como abacatinho (Ocotea sp.), andiroba (Carapa guianensis), pitomba-peluda (Sloanea guianensis), abiu (Pouteria sp.), cajuzinho (Anacardium giganteum) e outros, foram encontrados altos teores de energia (extrato etéreo médio= 19,64\%). Albuquerque et al. (2013a) também avaliaram os efeitos nutricionais do uso da torta de dendê no desempenho de caititus e do emprego do babaçu (Orbignya phalerata) como fonte energética (ALBUQUERQUE et al., 2013b). Santos e Nogueira-Filho (2012) estudaram a disponibilidade de frutos e o consumo dos caititus em 10 fruteiras arbóreas nativas em sistemas agroflorestais da lavoura cacaueira, identificando o Artocarpus heterophyllus como o principal recurso para o caititu nesta região enquanto a Cecropia hololeuca seria o recurso limitante.

Andrade et al. (2009) analisaram o consumo e a digestibilidade de diferentes frutos e co-produtos agrícolas regionais amazônicos (açaí, Euterpe oleracea; pupunha, Bactris gasipaes; casca e fruto de cupuaçu, Theobroma grandiflorum; jenipapo, Genipa americana; torta de dendê, Elaeis guineensis; quirera de arroz, Oriza sativa) na alimentação de caititus (P. tajacu) e queixadas (Tayassu pecari) em cativeiro, verificando que maiores níveis de fibra nesses alimentos reduziam o consumo e a digestibilidade mais em $P$. tajacu do que em T.pecari. Nogueira-Filho et al. (2018) ao testarem a capacidade dos caititus digerirem fibras, usando rações com ingredientes não-convencionais como a torta de dendê e a farinha de subprodutos da pupunha, verificaram também que há uma redução na ingestão com ingredientes com altos níveis de lignificação e umidade.

Considerando a eficiência alimentar dos caititus no aproveitamento de alimentos não tradicionais, fibrosos, como fonte de energia e seus baixos níveis de requerimento protéico, este estudo teve por objetivo avaliar os efeitos de níveis de substituição do milho por subprodutos como casca e 
torta do caroço de cupuaçu

(Theobroma grandiflorum), amêndoa do caroço de tucumã (Astrocaryum aculeatum) e torta da amêndoa do muru-muru (Astrocaryum murumuru) em rações para catetos sobre o desempenho desses animais em cativeiro.

\section{MATERIAL E MÉTODOS}

ÁREA, INSTALAÇÕES E ANIMAIS EXPERIMENTAIS

Os experimentos foram realizados nas instalações do Centro Experimental de Criação de Animais Nativos (CECAN), do Instituto Brasileiro do Meio Ambiente e dos Recursos Naturais Renováveis (IBAMA), localizado no km 35 da Rodovia BR174, em Manaus (latitude: 20 40'11.61"S; longitude: $60^{\circ} 02^{\prime} 56.06^{\prime \prime} \mathrm{O}$; altitude: 74 m).

Entre 2009 e 2011, durante quatro períodos experimentais distintos, os testes de desempenho foram conduzidos em quatro baias de 5,0 m de comprimento por 3,0 m de largura, medindo um total de $15 \mathrm{~m}^{2}$, localizadas num galpão de $360 m^{2}$, com 20 baias.
As baias possuíam duas áreas distintas. A primeira área media $10 \mathrm{~m}^{2}$ e possuía piso, recoberto de areia, com uma cerca de 2,0 m (0,8 m de mureta e 1,20 m de tela de alambrado malha 3", fio 14). A segunda área era coberta, medindo $5 \mathrm{~m}^{2}$, possuía piso de alvenaria e parede de 2,0 m de altura (1,6 $\mathrm{m}$ de alvenaria e 0,4 $\mathrm{m}$ de tela de alambrado), nesta área encontrava-se o cambiador, que permitia isolar e conter os animais, fornecendo uma maior segurança no manejo. Os comedouros localizavam-se na parte interna baia, e os bebedouros na parte externa.

Nos quatro períodos experimentais foram utilizados um total de 45 animais jovens (4 a 10 meses de idade), sendo 10 machos e 35 fêmeas, pesando $11,7 \pm 5,8 \quad$ e $\quad 13,7 \pm 4,8 \quad k g$, respectivamente. Para testar cada subproduto, em cada experimento foram utilizados 12 animais. Cada baia recebeu três animais marcados individualmente com brincos plásticos fixados na orelha direita e aplicação de microchips (transponders ISSO FDX-B 12mmX2mm, Animall Tag). 
Apenas no $1^{\circ}$ período experimental, para testar a casca de cupuaçu (Theobroma grandiflorum) foram usados somente 9 animais: 3 machos e 6 fêmeas, pesando 11,4 $43,8 \mathrm{~kg}$, com idade 6-10 meses. No segundo período, foi testada a torta do caroço de cupuaçu em12 animais: 2 machos e 10 fêmeas de seis meses de idade e $15 \pm 4,6 \mathrm{~kg}$ de peso vivo. No $3^{\circ}$ período foram usados os mesmos 12 animais do $2^{\circ}$ experimento,

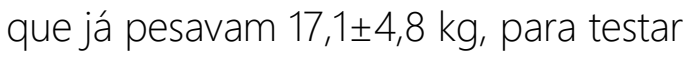
a torta de caroço de tucumã (Astrocaryum aculeatum). E no $4^{\circ}$. período foram utilizados outro grupo de 12 jovens animais, de 4 a 8 meses, sendo 3 machos e 9 fêmeas, pesando em média 9₫2,9kg para testar a torta de muru-muru.

\section{SUBPRODUTOS E RAÇÕES EXPERIMENTAIS}

Foram avaliados quatro subprodutos regionais: a casca e a torta do caroço ou amêndoa de cupuaçu (T.grandiflorum) e a amêndoa do caroço de tucumã (A.aculeatum), resíduos do despolpamento do fruto; e a torta do muru-muru (A.murumuru), resíduo da extração do óleo deste fruto de palmeira. A casca de cupuaçu foi oriunda da Fazenda Experimental da UFAM. A torta do caroço de cupuaçu foi obtida pela prensagem das sementes provenientes da empresa de beneficiamento de cupuaçu, CUPUAMA, localizada no município Careiro Castanho, a 102 km de Manaus.

Os caroços de tucumã foram adquiridos nas feiras de Manaus, onde o fruto, in natura, era despolpado e vendido, sendo o caroço descartado. Para a obtenção da amêndoa, os caroços foram submetidos à secagem em estufa, a $60{ }^{\circ} \mathrm{C}$ por 24 horas, para facilitar a quebra, que foi feita, posteriormente, de forma manual com auxílio de um martelo ou marreta. Após a quebra das cascas e a retirada das amêndoas, elas foram então trituradas em um moedor de carne elétrico (Desintegrador, PPM-4 da marca Nogueira), e após foram novamente submetidas à secagem em estufa, à $60^{\circ} \mathrm{C}$ por 24 horas. A torta da amêndoa do caroço de muru-muru (A. murumuru) foi adquirida nas usinas de extração de óleo de sementes para biodiesel da Associação dos Produtores Rurais de Carauari (ASPROC) na Reserva Extrativista 
do Médio Juruá em Carauari/AM. A

tabela 1 apresenta da composição bromatológica desses ingredientes.

Foi feita a análise bromatológica dos ingredientes (Tabela 1) e das rações experimentais (Tabelas 2 e 3 ) segundo as normas da Association of Official Analytical Chemists (AOAC, 2016). Os alimentos foram analisados na Central Analítica do Centro de Apoio Multidisciplinar (CAM) da Universidade Federal do Amazonas e no Centro de Pesquisa em Aquacultura (CPAQ) Instituto Nacional de Pesquisas na Amazônia.

Tabela 1. Análise proximal dos subprodutos agrícolas utilizados como ingredientes substitutos do milho em rações para caitetus (Pecari tajacu) mantidos em cativeiro na Amazônia Central, Manaus - AM.

\begin{tabular}{l|l|l|l|l|l|l|l}
\hline Alimento & $\%$ MS & $\begin{array}{l}\% \\
\text { MM }\end{array}$ & \% PB & $\%$ FB & $\%$ EE & $\begin{array}{l}\% \\
\text { ENN }\end{array}$ & $\begin{array}{l}\text { Energia } \\
\text { (kcal/kg) }\end{array}$ \\
\hline Casca de cupuaçu in natura & 37,3 & 9,1 & 3,4 & 76,0 & 1,3 & 10,2 & 3892 \\
Casca de cupuaçu, triturada e & 96,6 & 2,6 & 2,9 & 48,2 & 0,7 & 42,2 & 4089 \\
seca & & & & & & & \\
Torta de caroço de cupuaçu & 89,7 & 5,3 & 13,1 & 30,6 & 10,2 & 40,8 & 4662 \\
Caroço de cupuaçu & 94,7 & 1,4 & 4,1 & 4,2 & 12,2 & 12,4 & 1323 \\
Amêndoa de tucumã & 94,7 & 1,9 & 5,3 & 37,8 & 7,8 & 47,3 & 4564 \\
Amêndoa de murumuru & 90,7 & 1,5 & 13,1 & 9,6 & 26,3 & 40,2 & 5279 \\
Torta de murumuru & 80,2 & 2,1 & 9,7 & 25,9 & 3,1 & 59,2 & 4371 \\
\hline
\end{tabular}

Obs: $M S=$ Matéria seca; $M M=$ Matéria mineral; $\mathrm{PB}=$ Proteína bruta; FB= Fibra bruta; $\mathrm{EE}=$ Extrato etéreo; ENN=Extrativo Não nitrogenado.

Para cada período experimental foram elaborados quatro tipos de rações: $\mathrm{T0}=$ ração controle com ingredientes tradicionais milho triturado e farelo de soja tostado; $\mathrm{T} 10=$ ração com 10\% de subproduto $(16,7 \%$ de substituição do milho); T20= ração com $20 \%$ de subproduto $(33,3 \%$ de substituição do milho); T30= ração com
$30 \%$ de subproduto $(50 \%$ de substituição do milho). Em cada período experimental foi utilizado um subproduto diferente como substituto do milho como fonte energética. As Tabelas 2 e 3 apresentam os ingredientes, a composição e os valores nutricionais das rações experimentais analisadas. 
Tabela 2. Composição percentual, caracterização química e nutricional em porcentagem dos ingredientes das rações dos experimentos com níveis crescentes subprodutos do cupuaçu (Theobroma grandiflorum) - casca triturada e torta do caroço - na alimentação de caitetus (Pecari tajacu) em cativeiro.

\begin{tabular}{l|c|c|c|c|c|c|c}
\hline Componentes das rações & \multicolumn{3}{|c|}{ Experimento 1: casca } & \multicolumn{3}{|c}{ Experimento 2: torta da amêndoa } \\
\hline Ingredientes/Tratamentos $^{1}$ & T0 & T10 & T30 & T0 & T10 & T2 & T30 \\
\hline Milho (kg) & 60 & 50 & 30 & 60 & 50 & 40 & 30 \\
Farelo de Soja (kg) & 40 & 40 & 40 & 40 & 40 & 40 & 40 \\
Casca de cupuaçu (kg) & 0 & 10 & 30 & - & - & - & - \\
Torta de amêndoa de cupuaçu & & & & & & & \\
(kg) & - & - & - & 0 & 10 & 20 & 30 \\
Sal (kg) & 0,5 & 0,5 & 0,5 & 0,5 & 0,5 & 0,5 & 0,5 \\
Premix mineral e vitamínico ${ }^{2}$ (kg) & 0,3 & 0,3 & 0,3 & 0,3 & 0,3 & 0,3 & 0,3 \\
\hline Nutrientes ${ }^{3}$ & \multicolumn{7}{|c|}{ Composições químico-bromatológicas das rações (\%) } \\
\hline \%MS & 87,9 & 82,9 & 72,9 & 88,6 & 88,8 & 88,2 & 89,2 \\
\%UM & 12,1 & 17,1 & 27,1 & 11,4 & 11,2 & 11,8 & 10,8 \\
\%MM & 3,5 & 4,2 & 5,7 & 3,8 & 4,3 & 4,7 & 4,5 \\
\%MO & 96,5 & 95,8 & 94,3 & 84,9 & 84,5 & 83,4 & 84,7 \\
\%PB & 23,3 & 22,8 & 21,8 & 21,2 & 22,3 & 20,3 & 22,6 \\
\%EE & 2,3 & 2,1 & 1,7 & 3,6 & 3,9 & 5,5 & 5,9 \\
\%FB & 3,6 & 11,2 & 26,3 & 3,6 & 6,5 & 9,4 & 12,3 \\
\%ENN & 55,1 & 48,9 & 36,6 & 55,1 & 52,0 & 48,9 & 45,8 \\
\hline
\end{tabular}

1. Tratamentos: $\mathrm{TO}=$ ração controle; $\mathrm{T} 10=$ ração $\mathrm{com} 10 \%$ de subproduto $(16,7 \%$ de substituição do milho); $T 20=$ ração com $20 \%$ de subproduto (33,3\% de substituição do milho); $T 30=$ ração com 30\% de subproduto ( $50 \%$ de substituição do milho).

2. Nucleomix NP4 - 0,4\% - Premix Mineral Vitamínico Composição: Vitamina A (2000000,00 UI), Vitamina D3 (500000,00 UI), Vitamina E (1250,00 mg), Vitamina K3 (500,00 mg), Vitamina B2 $(1000,00$ mg), Vitamina B12 (1750,00 mg), Ácido Nicotínico (5000,00 mg), Pantetonato de Cálcio (1250,00 mg), BHA (5,00 mg), Etoxiquin (6,25 mg), Colistina (1000 mg), Metionina (300000,00 mg), Colina (38775,00 mg), Cobre (17500,00 mg), Ferro (10000,00 mg), Manganês (15000,00 mg), Zinco (12500,00 mg), lodo (175,00 mg), Selênio (50,00 mg).

3. $M S=$ Matéria seca; $U M=$ Umidade; $M M=$ Matéria mineral; $M O=$ Matéria orgânica; $P B=$ Proteína bruta; $\mathrm{EE}=$ Extrato etéreo; $\mathrm{FB}=$ Fibra bruta; $\mathrm{ENN}=$ Extrativo Não nitrogenado

No período experimental quatro, em função da dificuldade logística de transportar o ingrediente torta de semente de murumuru (A.murumuru) de Carauari até Manaus, foi necessário reduzir sua quantidade nos tratamentos. Sendo que, apenas para esse período experimental, os tratamentos foram: T0=tratamento controle; $\mathrm{T} 9=$ tratamento com $9 \%$ de subproduto (15\% de substituição ao milho); T15= tratamento com 15\% do subproduto (25\% de substituição ao milho); T30= tratamento com $30 \%$ do subproduto (50\% de substituição ao milho) (Tabela 3). 
Tabela 3. Composição percentual, caracterização química e nutricional em porcentagem dos ingredientes das rações dos experimentos com níveis crescentes de amêndoa de tucumã (Astocaryum aculeatum) e de torta de amêndoa de muru-muru (A.murumuru) na alimentação de caitetus (Pecari tajacu) em cativeiro.

\begin{tabular}{|c|c|c|c|c|c|c|c|c|}
\hline \multirow{2}{*}{$\begin{array}{l}\text { Componentes das rações } \\
\text { Ingredientes/Tratamentos }^{1}\end{array}$} & \multicolumn{4}{|c|}{ Experimento 3: tucumã } & \multicolumn{4}{|c|}{$\begin{array}{l}\text { Experimento 4: torta de } \\
\text { murumuru }\end{array}$} \\
\hline & TO & $\mathrm{T} 10$ & $\mathrm{~T} 20$ & $\mathrm{~T} 30$ & T0 & T9 & T15 & $\mathrm{T} 30$ \\
\hline Milho $(\mathrm{kg})$ & 60 & 50 & 40 & 30 & 60 & 51 & 45 & 30 \\
\hline Farelo de Soja (kg) & 40 & 40 & 40 & 40 & 40 & 40 & 40 & 40 \\
\hline Amêndoa de tucumã (kg) & 0 & 10 & 20 & 30 & . & - & - & - \\
\hline $\begin{array}{l}\text { Torta de amêndoa de murumuru } \\
(\mathrm{kg})\end{array}$ & - & - & - & - & 0 & 9 & 15 & 30 \\
\hline Sal (kg) & 0,5 & 0,5 & 0,5 & 0,5 & 0,4 & 0,4 & 0,4 & 0,4 \\
\hline Premix mineral e vitamínico ${ }^{2}(\mathrm{~kg})$ & 0,3 & 0,3 & 0,3 & 0,3 & 0,4 & 0,4 & 0,4 & 0,4 \\
\hline Nutrientes $^{3}$ & \multicolumn{8}{|c|}{ Composições químico-bromatológicas das rações (\%) } \\
\hline$\% M S$ & 88,8 & 89,6 & 89,7 & 90,2 & 87,9 & 87,3 & 86,8 & 85,7 \\
\hline$\% \cup M$ & 11,2 & 10,4 & 10,3 & 9,8 & 12,1 & 12,7 & 13,1 & 14,2 \\
\hline$\% M M$ & 4,0 & 3,3 & 4,0 & 3,8 & 3,5 & 3,5 & 3,5 & 3,6 \\
\hline$\% \mathrm{MO}$ & 84,8 & 86,2 & 85,7 & 86,4 & 96,5 & 96,5 & 96,5 & 96,4 \\
\hline$\% \mathrm{~PB}$ & 17,3 & 21,6 & 20,1 & 17,3 & 23,4 & 23,4 & 23,5 & 23,7 \\
\hline$\% \mathrm{EE}$ & 3,3 & 5,8 & 8,1 & 10,7 & 2,3 & 2,3 & 2,2 & 2,2 \\
\hline$\% F B$ & 3,6 & 7,2 & 10,9 & 14,5 & 3,6 & 5,8 & 7,3 & 10,9 \\
\hline$\%$ ENN & 55,1 & 52,7 & 50,2 & 47,7 & 55,1 & 54,0 & 53,2 & 51,3 \\
\hline
\end{tabular}

1. Tratamentos: $\mathrm{TO}=$ ração controle; $\mathrm{T} 10=$ ração com $10 \%$ de subproduto $(16,7 \%$ de substituição do milho); $T 20=$ ração com 20\% de subproduto (33,3\% de substituição do milho); $T 30=$ ração com 30\% de subproduto (50\% de substituição do milho); T9=ração com 9\% de subproduto (15\% de substituição do milho); $T 15=$ ração com $15 \%$ de subproduto (25\% de substituição do milho).

2. Nucleomix NP4 - 0,4\% - Premix Mineral Vitamínico Composição: Vitamina A (2000000,00 UI), Vitamina D3 (500000,00 UI), Vitamina E (1250,00 mg), Vitamina K3 (500,00 mg), Vitamina B2 (1000,00 mg), Vitamina B12 (1750,00 mg), Ácido Nicotínico (5000,00 mg), Pantetonato de Cálcio (1250,00 mg), BHA (5,00 mg), Etoxiquin (6,25 mg), Colistina (1000 mg), Metionina (300000,00 mg), Colina (38775,00 mg), Cobre (17500,00 mg), Ferro (10000,00 mg), Manganês (15000,00 mg), Zinco (12500,00 mg), lodo (175,00 mg), Selênio (50,00 mg).

3. $M S=$ Matéria seca; $U M=$ Umidade; $M M=$ Matéria mineral; $M O=$ Matéria orgânica; $P B=$ Proteína bruta; $\mathrm{EE}=$ Extrato etéreo; $\mathrm{FB}=$ Fibra bruta; $\mathrm{ENN}=$ Extrativo Não nitrogenado

\section{METODOLOGIA}

Em cada experimento, os animais receberam as rações experimentais durante 60 dias, sendo medidos e pesados no início e no fim desse período. A quantidade de alimento fornecido e as sobras foram registradas a cada dois dias, sendo que as sobras das rações foram descartadas. $\bigcirc$ consumo diário foi registrado em 
planilhas de campo. Todas as ocorrências do comportamento de consumo do alimento foram observadas. Foram registradas e analisadas as variáveis peso final (kg), ganho diário em peso (g/dia), consumo diário (g), consumo em percentual de peso vivo (\%), conversão alimentar e custos das rações.

\section{ANÁLISE ESTATÍSTICA}

O experimento foi feito em um delineamento inteiramente ao acaso com 4 tratamentos (T0, T10, T20 e T30 com crescentes níveis de inclusão de diferentes subprodutos em substituição ao milho nas rações) e 3 repetições (3 animais por tratamento, cada animal sendo considerado uma repetição). Para as variáveis analisadas, verificouse parâmetros de estatística descritiva (média, desvio padrão, variância, coeficiente de variação) e foram aplicados testes de normalidade (testes de Anderson-Darling e Ryan-Joiner) e igualdade de variâncias (teste de Bartlett). Em função dos jovens animais utilizados nos experimentos, possuírem idades e tamanhos um pouco heterogêneos, utilizamos o peso inicial dos animais como covariável na análise dos resultados.

Depois aplicou-se a ANOVA com covariância do peso inicial para todas as variáveis analisadas. As médias das variáveis analisadas foram comparadas pelo teste $F$ e de Tukey. Também, verificou-se a correlação (Pearson) entre as variáveis e os níveis crescentes de subprodutos utilizados e, posteriormente, quando a correlação foi significativa $(P<0,05)$, aplicou-se a análise de regressão linear e quadrática.

Os pacotes estatísticos utilizados foram o MINITAB ${ }^{\text {TM }}$ Stastical Software 13.0 e o PAST 2.08.

\section{ASPECTOS ÉTICOS E LEGAIS}

Registro

IBAMA

N.1/13/1999/000028-1, SISFAUNA 281126 e Comitê de ética no Uso de Animais (CEUA\}-UFAM No.097/2010.

\section{RESULTADOS E DISCUSSÃO}

A análise bromatológica dos quatro subprodutos utilizados (casca e torta de caroço de cupuaçu; amêndoa do 
caroço de tucumã; e torta de amêndoa de murumuru) como ingredientes em substituição ao milho como fonte energética, foi apresentada na tabela 1. E a composição químico-bromatológica de todas as rações experimentais foram apresentadas nas Tabelas 2 e 3.

Verificou-se que a casca de cupuaçu (T.grandiflorum) in natura apresenta elevado teor de umidade (UM=62,7\%) em relação a casca triturada e seca que foi utilizada como ingrediente das rações. Mas tanto a casca de cupuaçu in natura e a casca triturada e seca possuem, respectivamente, maiores valores de fibra bruta ( $F B=76$ e 48,2\%), menores níveis de proteína bruta $(P B=3,4$ e 2,9\%) e valores similares de extrato etéreo ( $E E=1,3$ e 0,7\%) que o milho em grãos ( $F B=1,8 \% ; P B=8,8 \%$; $E E=1,4 \%-$ ROSTAGNO et al., 2000). As rações com níveis crescentes de casca de cupuaçu em substituição ao milho, apresentaram maiores valores de umidade e fibra em relação a ração controle, com valores similares em proteína e extrato etéreo (Tabela 2). Já a torta do caroço de cupuaçu (T.grandiflorum) apresentou teores de proteína bruta, extrato etéreo e fibra bruta $\quad(P B=12,13 \% ; \quad E E=10,18 \%$; $\mathrm{FB}=30,6 \%$ ) superiores aos teores normalmente encontrados no milho (ROSTAGNO et al., 2000). Mas os valores de matéria orgânica $(\mathrm{MO})$ e matéria seca (MS) da torta do caroço de cupuaçu $\quad(\mathrm{MO}=\quad 84,45 \%$; $M S=89,73 \%)$ e do milho $(M O=85,8 \%$; $M S=87,1 \%) \quad$ são semelhantes. Observou-se, também na tabela 2, que os níveis proteicos das rações com níveis crescentes de torta de caroço de cupuaçu variaram pouco (20,3 a 22,6\%PB) em relação a ração controle (21,2\%PB). Entretanto, houve um aumento no extrato etéreo e na fibra bruta das rações, à medida que aumentamos os níveis de torta de caroço de cupuaçu nas rações.

Apesar da utilização dos ingredientes casca e torta de caroço de cupuaçu conferirem níveis mais elevados de fibra em relação a ração controle, deve-se considerar que os caititus são anatômica e fisiologicamente adaptados para digerir fibras (SCHWARM et al., 2010), e que nenhuma das rações 
experimentais ultrapassaram 30 a 35\% de fibra o que afetaria a digestibilidade das dietas (NOGUEIRA-FILHO, 2005). Considerando ainda que os valores de proteínas e de extrato etéreo das rações com casca e torta de caroço foram similares a ração controle, esses ingredientes poderiam ser bons substitutos para o milho como fonte de energia (EBmilho=3500 a $3800 \mathrm{kcal} / \mathrm{kg}$, ROSTAGNO et al., 2000).

A amêndoa de tucumã (A.aculeatum) apresentou maiores valores de fibra e extrato etéreo ( $F B=37,8 \% ; E E=7,8 \%)$ e menores valores de proteína ( $P B=5,3 \%)$ que os valores encontrados para o milho (ROSTAGNO et al., 2000). As raçÕes com níveis crescentes de amêndoa triturada de tucumã, consequentemente, também apresentaram maiores níveis de fibra e gordura e menor quantidade de proteína e umidade em relação a ração controle (Tabela 3). Já a torta da amêndoa de murumurun (A. murumuru) apresentou maiores valores de fibra, gordura e proteína ( $F B=25,9 \%$; EE=3,1\%; PB $=9,7 \%$ ) em relação ao milho em grão, além de possuir muito mais umidade (UM=19,8\%). As rações com níveis crescentes de torta de murumuru também apresentaram maior umidade e fibra em relação a ração controle, mas tiveram valores de proteína e de gordura similares a ração controle. Então, tanto a amêndoa do tucumã, quanto a torta da amêndoa de murumuru poderiam ser também, bons substitutos do milho como fonte de energia na ração.

A tabela 4 apresenta os resultados das variáveis de desempenho zootécnico dos caititus ( $P$. tajacu) alimentados com as rações experimentais com os diferentes subprodutos.

Caitetus jovens (4 a 6 meses) que foram alimentados com níveis crescentes $(0,10,20$ e 30\%) de casca de cupuaçu (triturada e seca) em substituição ao milho tiveram, ao final de 60 dias, em média peso final igual a 16,6 $\pm 3,7 \quad k g \quad$ (máximo=20 kg; mínimo=11,5kg; coeficiente de variação-CV=22,5\%). Houve diferença significativa $\quad$ (ANOVA:P<0,0001; ANCOVA: $P<0,03)$ no peso de animais alimentados com diferentes níveis de farinha de casca de cupuaçu (Tabela 4). 
Tabela 4. Peso final (kg), ganho diário em peso (g/dia) e conversão alimentar de caitetus (Tayassu tajacu) em cativeiro alimentados com rações com diferentes níveis de substituição do milho por subprodutos agrícolas amazônicos

\begin{tabular}{|c|c|c|c|c|c|}
\hline Subproduto & Variável $^{1}$ & $\begin{array}{c}\text { Ração } \\
\text { controle }\end{array}$ & $\begin{array}{l}\text { Ração com } \\
10 \% \text { de } \\
\text { subproduto }\end{array}$ & $\begin{array}{l}\text { Ração com } \\
20 \% \text { de } \\
\text { subproduto } \\
\end{array}$ & $\begin{array}{l}\text { Ração com } \\
30 \% \text { de } \\
\text { subproduto }\end{array}$ \\
\hline $\begin{array}{l}\text { Casca de } \\
\text { cupuaçu }\end{array}$ & $\begin{array}{l}\text { Peso Final }(\mathrm{kg})^{\star \star \star} \\
\text { Ganho em peso (g/dia) } \\
\text { Conversão Alimentar }\end{array}$ & $\begin{array}{c}18,8 \pm 0,8^{a} \\
76,5 \pm 33 \\
3,7 \pm 1,3\end{array}$ & $\begin{array}{c}19,2 \pm 1^{a} \\
95,6 \pm 53 \\
3,3 \pm 1,5 \\
\end{array}$ & $\begin{array}{l}- \\
- \\
- \\
\end{array}$ & $\begin{array}{l}11,7 \pm 0,3^{b} \\
80,6 \pm 12 \\
3,3 \pm 0,5 \\
\end{array}$ \\
\hline $\begin{array}{l}\text { Torta de } \\
\text { caroço de } \\
\text { cupuaçu }\end{array}$ & $\begin{array}{l}\text { Peso Final }(\mathrm{kg})^{\star \star \star} \\
\text { Ganho em peso (g/dia) } \\
\text { Conversão Alimentar }\end{array}$ & $\begin{array}{c}19,3 \pm 1,2^{b} \\
5 \pm 2^{c} \\
2,5 \pm 6\end{array}$ & $\begin{array}{l}23 \pm 1,7^{a} \\
59 \pm 33^{a} \\
3,4 \pm 2,7\end{array}$ & $\begin{array}{c}13,3 \pm 3,3^{c} \\
48 \pm 17^{a} \\
2,4 \pm 0,6\end{array}$ & $\begin{array}{l}13 \pm 0,5^{c} \\
19 \pm 11^{b} \\
9,4 \pm 7,3\end{array}$ \\
\hline $\begin{array}{l}\text { Amêndoa } \\
\text { de tucumã }\end{array}$ & $\begin{array}{l}\text { Peso Final (kg) } \\
\text { Ganho em peso (g/dia) } \\
\text { Conversão Alimentar }\end{array}$ & $\begin{array}{c}17 \pm 1,3 \\
49,3 \pm 21 \\
7,9 \pm 4,6 \\
\end{array}$ & $\begin{array}{c}17 \pm 4,5 \\
56,3 \pm 12,2 \\
8,3 \pm 2,3 \\
\end{array}$ & $\begin{array}{c}24 \pm 1,7 \\
12,2 \pm 38,1 \\
11,9 \pm 14,3 \\
\end{array}$ & $\begin{array}{c}20,3 \pm 2,9 \\
21,1 \pm 32,3 \\
6,9 \pm 6,6 \\
\end{array}$ \\
\hline $\begin{array}{l}\text { Torta de } \\
\text { amêndoa } \\
\text { de muru- } \\
\text { muru }\end{array}$ & $\begin{array}{l}\text { Peso Final }(\mathrm{kg})^{\star \star \star} \\
\text { Ganho em peso }(\mathrm{g} / \mathrm{dia})^{\star \star} \\
\text { Conversão Alimentar }\end{array}$ & $\begin{array}{c}7,8 \pm 1,2^{c} \\
44,4 \pm 10^{b} \\
5,3 \pm 3\end{array}$ & $\begin{array}{c}13,3 \pm 1,5^{a} \\
14,8 \pm 12,5^{c} \\
2,7 \pm 2,4\end{array}$ & $\begin{array}{c}11,2 \pm 1,2^{a} \\
74,1 \pm 5,7^{a} \\
5,1 \pm 0,8\end{array}$ & $\begin{array}{c}10,2 \pm 0,8^{a b} \\
7,4 \pm 7,6^{c} \\
4,1 \pm 5,8\end{array}$ \\
\hline
\end{tabular}

1. Variáveis seguidas de asteriscos $\left({ }^{*}\right)$ diferem significativamente pelo teste $F$ da ANOVA, sendo: ${ }^{*}=(P<0,05) ;{ }^{* *}=(P<0,01) ;{ }^{* \star *}=(P<0,001)$;

2. Médias seguidas da mesma letra, nas linhas, não diferem significativamente pelo teste de Tukey $(P<0,01)$.

Os pesos médios dos animais alimentados com a ração controle $(18,8 \pm 0,76$ kg) e com a ração com 10\% de casca de cupuaçu $(19,2 \pm 1,04 \mathrm{~kg})$, foram superiores ao peso dos animais que receberam ração com 30\% de casca $(11,7 \pm 0,29 \mathrm{~kg})$, pelo teste de Tukey $(P<0,01)$. Foi observada uma relação linear entre o nível de farinha de casca de cupuaçu e o peso final, sendo a regressão significativa $(P<0,001 ; R 2=84 \%)$, quanto maior foi o nível de casca de cupuaçu na ração, menor o peso final dos caititus (Figura 1). Em relação ao ganho diário em peso (GDP), embora tenha sido detectada uma diferença entre os tratamentos (ANCOVA:P<0,003), mas não foi possível verificar diferença entre as médias de GDP pelo teste de Tukey.

Com relação ao consumo em percentual do peso vivo, houve diferença significativa entre os tratamentos (ANOVA:P $<0,0001$ ANCOVA:P $<0,007)$ sendo que, animais alimentados como ração 
controle e ração com 10\% de casca tiveram consumos similares $(1,61 \pm 0,1 \%$

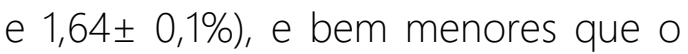
consumo dos que comeram ração com $30 \%$ de casca $(2,9 \pm 0,2 \%)$, pelo teste de Tukey $(P<0,0001)$. A regressão linear entre o nível de farinha de casca na ração e o percentual de consumo também foi significativa $\left(P<0,0001 ; R^{2}=\right.$ 87,8\%), quanto maior foi o nível de substituição do milho pela casca de cupuaçu, maior foi o consumo (Figura 2). Não foram encontradas diferenças entre a conversão alimentar dos animais alimentados com as rações controle e rações com diferentes níveis de casca de cupuaçu.

Aparentemente, os caititus alimentados com maior nível de casca de cupuaçu (30\%) comeram mais ração em função, principalmente, do maior nível de umidade (ração menos seca) e do maior nível de fibra desta dieta (26,4\%), e sua consequente, redução na digestibilidade e disponibilidade dos demais nutrientes, já que a variação de energia entre essas rações foi pequena (T0=3968 kcal/kg; T10=3979 kcal/kg; $\mathrm{T} 30=4002 \mathrm{kcal} / \mathrm{kg}$ ).

Figura 1. Regressão linear entre os níveis de casca de cupuaçu (T. grandiflorum) em rações e os pesos finais $(\mathrm{kg})$ de caititus ( $P$. tajacu) em cativeiro.

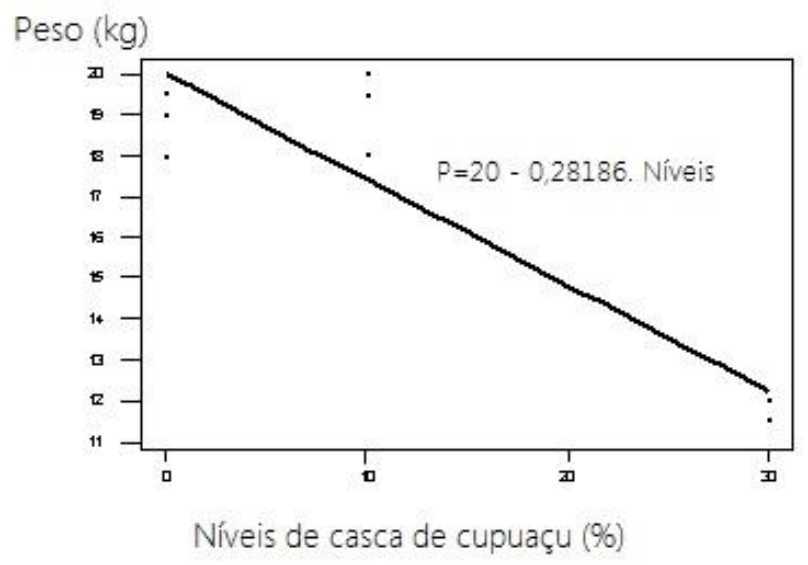


Figura 2. Regressão linear entre os níveis de casca de cupuaçu (T. grandiflorum) em rações e o consumo diário em percentual do peso vivo (\%PV) de caititus (P. tajacu) em cativeiro.

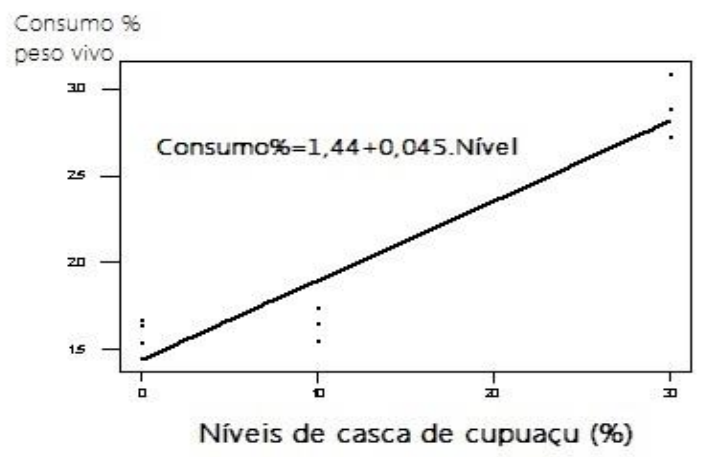

Andrade et al. (2009) e NogueiraFilho et al. (2018), entretanto, verificaram que, os caititus reduzem seu consumo e digestibilidade em dietas com altos níveis de fibra e umidade. Além disso, Andrade et al. (2009) observou ainda que, em testes de preferência alimentar com diferentes subprodutos, que a casca seca e triturada de cupuaçu foi o alimento mais rejeitado pelos caitetus, com um consumo médio por quilo de peso vivo igual a $3,5 \pm 3,4 \mathrm{~g} / \mathrm{kg}$ de peso vivo (valor superior aos encontrados no presente estudo), o que atribuiu ao elevado teor de fibra do produto e a sua baixa palatabilidade. Talvez a diferença encontrada quanto as tendências de consumo em rações com maior nível de fibra entre esses dois estudos e o presente trabalho deva-se ao fato de Andrade et al. (2009) e Nogueira-Filho et al. (2018) terem trabalhado com machos adultos de caititus $(20,4 \pm 1,7 \mathrm{~kg}$ e $21.8+0.5 \mathrm{~kg}$, respectivamente), enquanto, neste experimento trabalhou-se, principalmente com fêmeas jovens $(11,7 \pm 4,3 \mathrm{~kg})$. O que talvez, também afete a percepção dos animais quanto a palatabilidade da casca de cupuaçu.

A casca de cupuaçu é um subproduto agrícola da extração da polpa do fruto, não tendo valor 
comercial, observou-se que sua utilização em níveis de até 10\% na ração, substituindo 16,7\% do milho propiciou uma redução de 12,3\% no custo de um quilo de ração, sendo igual a $\mathrm{R} \$ 0,75 / \mathrm{kg}$ que foi inferior ao da ração controle, $R \$ 0,86 / \mathrm{kg}$.

Caitetus que foram alimentados com diferentes níveis de torta de caroço de cupuaçu em substituição ao milho tiveram, ao final de 60 dias, peso médio final igual a $17,1 \pm 4,7 \mathrm{~kg}$ (máximo=24kg; mínimo=10,5kg; coeficiente de variação-CV=27,4\%). Houve diferença significativa (ANOVA: $P<0,001 ; \quad A N C O V A: P<0,021)$ entre os pesos finais dos tratamentos (Tabela 4). Os animais que tiveram os maiores pesos médios finais, pelo teste de Tukey $(P<0,01)$ foram os alimentados com ração com 10\% de torta de caroço de cupuaçu e com a ração controle, e os animais com níveis de 20 e 30\% de inclusão do subproduto, obtiveram os menores pesos. Foi detectada relação significativa entre os níveis de torta de caroço de cupuaçu nas rações e o peso final dos animais (linear: $\mathrm{P}<0,01$; quadrática: $P<0,03)$, sendo que, que quanto maior o nível de subproduto, menor foi o peso final. A regressão quadrática foi a que melhor explicou as variações do peso final em função dos níveis do subproduto $\left(R^{2}=53,3 \%\right.$; Figura 3).

Figura 3. Regressão quadrática entre os níveis de torta de caroço de cupuaçu ( $T$. grandiflorum) em rações e os pesos finais $(\mathrm{kg})$ de caititus ( $P$. tajacu) em cativeiro.

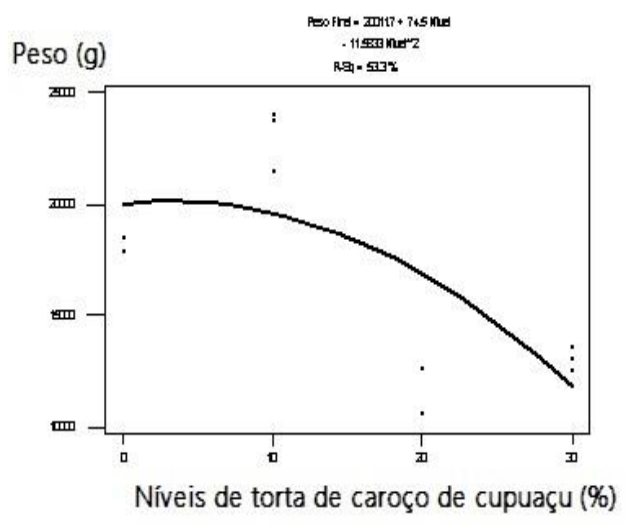


Também houve diferença significativa no ganho diário em peso (ANOVA: $P<0,03 ;$ ANCOVA: $P<0,02$ ) de caititus alimentados com rações com níveis crescentes de torta de caroço de cupuaçu. Os animais com melhor ganho de peso foram os que receberam ração com 10\% de inclusão de torta de cupuaçu $(59 \pm 33 \mathrm{~g} /$ dia $)$ e os que ganharam menos peso foram os da ração controle ( $5 \pm 3 \mathrm{~g} / \mathrm{dia})$, pelo teste de Tukey $(P<0,02)$. Não foi encontrada regressão entre os níveis de torta de caroço de cupuaçu nas rações e o GDP dos animais.

Não houve diferença significativa $(P=0,176) \quad$ no consumo diário $(\mathrm{T} 0=117,6 \pm 0,1 ; \quad \mathrm{T} 10=\quad 129,8 \pm 0,1 ;$ $\mathrm{T} 20=110,3 \pm 3,0 ; \quad T 30=117,2 \pm 0,1 \mathrm{~g} / \mathrm{dia})$ e no consumo diário em percentual do peso vivo $(\mathrm{T} 0=0,62 \quad \pm 0,01 \%$; $\mathrm{T} 10=0,6 \pm 0,02 \% ; \quad \mathrm{T} 20=1 \pm 0,3 \% ; \quad \mathrm{T} 30=$ 1士0,01\%). Também não houve diferença significativa na conversão alimentar média entre os animais alimentados com diferentes níveis deste subproduto (ANOVA:P=0,09; ANCOVA:P=0,25).
A substituição do milho por níveis crescentes de torta de caroço de cupuaçu, aparentemente, teve um efeito quadrático sobre o peso final e o ganho de peso dos animais, apresentando como nível ótimo de inclusão de $10 \%$ do subproduto, quando os índices de desempenho (peso final, ganho de peso, consumo em percentual do peso vivo) tendem a ser melhores. À medida que se elevaram os níveis de inclusão de torta de caroço de cupuaçu para 20 e 30\% e, consequentemente, aumentou-se o nível de fibra bruta e de gordura nas rações, os animais tenderam a apresentar resultados inferiores de peso, ganho de peso e conversão alimentar.

Andrade et al. (2009) ao realizar testes de preferência alimentar em caititus (P. tajacu) e queixadas (Tayassu pecari) para alguns frutos amazônicos, verificaram que os queixadas chegam a consumir 915,8土146 g de caroços e polpa de cupuaçu por dia, estando entre os frutos que registraram maior consumo diário juntamente com a 
pupunha (Bactris gasipaes) e o açaí (Euterpe oleracea). Estes autores não encontraram uma correlação direta entre o consumo médio e os níveis de gordura (extrato etéreo) e de energia bruta $(\mathrm{kcal} / \mathrm{kg})$ dos frutos que testaram, tanto para caitetus quanto para queixadas. Entretanto, à medida que aumentou o nível de fibra bruta na composição dos alimentos houve uma redução no consumo.

A torta do caroço de cupuaçu é resíduo da fabricação de cosméticos a base de óleo de cupuaçu, por isso não possui valor de mercado, sendo necessário apenas os gastos com o transporte, equivalente a $\mathrm{R} \$ 0,18$ o quilograma do subproduto, tornando-o mais viável economicamente do que o milho, que possui o valor de $\mathrm{R} \$ 0,56$ o quilograma. A torta de caroço de cupuaçu tem um preço que é apenas $32 \%$ do valor do milho, sendo que, a sua inclusão em diferentes níveis nas rações poderá reduzir o valor do quilo da ração de 5 a 13\% (R\$0,82 a 0,75kg) em relação a ração controle $(R \$ 0,86 / \mathrm{kg})$. A ração mais barata foi a com 30\% de torta de caroço de cupuaçu em substituição ao milho $(R \$ 0,75 / \mathrm{kg})$.

No experimento com níveis crescentes de torta de amêndoa de tucumã (Astrocaryum aculeatum) em substituição ao milho nas rações para caitetus, não houve diferença significativa (ANOVA:P=0,05; ANCOVA: $P=0,79)$ no peso médio final dos animais, 19,5 $\pm 3,9 \mathrm{~kg}$ (máximo=25 kg; mínimo=14kg; CV=19,8\%), embora, se verifique uma tendência de animais que receberam maiores níveis de amêndoa de tucumã na sua alimentação, serem mais pesados (24 \pm 1,7 kg) em relação ao controle $(17,0 \pm 1,3$ kg). Também não foi encontrada diferença significativa no ganho diário em peso (tabela 4). Quanto ao consumo diário em gramas (g/dia) e em percentual do peso vivo (\%), não houve diferença significativa entre os tratamentos (TO=387,5 g/dia e 2,6\%; $\mathrm{T} 10=392 \mathrm{~g} / \mathrm{dia}$ e 2,6\%; T20=396 g/dia e 1,7\%; $\quad \mathrm{T} 30=372 \mathrm{~g} / \mathrm{dia}$ e 1,9\%, respectivamente). Não houve diferença significativa na conversão alimentar dos 
animais alimentados com diferentes níveis de amêndoa de tucumã nas rações.

Em relação ao custo das rações, deve-se considerar que, o caroço do tucumã, resíduo da retirada da polpa deste fruto para preparo de sanduíches em Manaus, que antes era descartado em grandes quantidades, passou a ser utilizado, justamente para extração da amêndoa para uso em rações ou para confecção de biojóias, o que elevou seu custo para $\mathrm{R} \$ 0,71 / \mathrm{kg}$ superior ao custo do milho em grão $(R \$ 0,56 / \mathrm{kg})$. Desta forma, a ração controle acaba saindo $5,5 \%$ mais barata $(R \$ 0,86 / \mathrm{kg})$ que a ração com a inclusão de $30 \%$ de amêndoa de tucumã $(R \$ 0,91)$.

Considerando-se que maiores níveis de amêndoa de tucumã aumentaram os níveis de fibra e gordura nas rações, e que isso pode afetar a digestibilidade dos nutrientes (Nogueira-Filho et al., 2018), e verificando-se ainda que rações com níveis elevados deste subproduto, tendem a reduzir o ganho de peso e o consumo, e a aumentar os custos, sugere-se uma inclusão de, no máximo
10\% de amêndoa de tucumã na substituição do milho.

No experimento em que foi utilizada a torta da amêndoa do muru-muru (Astrocaryum murumuru), os animais apresentaram, em média, peso final igual a 10,6 $22,3 \mathrm{~kg}$ (máximo=15kg; mínimo=6,5kg; CV=21,8\%). Na tabela 4, observa-se que houve diferença significativa no peso final médio dos animais $(P<0,001)$, sendo que $O$ tratamento com nível de 9\% de torta de murumuru em substituição ao milho apresentou maior peso $(13,3 \pm 1,5 \mathrm{~kg})$ que a ração controle, pelo teste de Tukey. Houve diferença significativa $(P<0,04)$ no ganho diário em peso dos animais (GDP $=36,0 \pm 33,5 \mathrm{~g} / \mathrm{dia}$ ), sendo que o tratamento com $15 \%$ de torta de murumuru apresentou $\mathrm{o}$ melhor resultado de ganho diário em peso, pelo teste de Tukey $(P<0,01)$. Não houve regressão significativa entre os níveis do subproduto e o peso final e ganho em peso dos animais. Não foram encontradas diferenças significativas tanto para o consumo diário de ração, consumo em percentual do peso vivo e 
para conversão alimentar de animais alimentados com diferentes níveis deste subproduto.

A torta de murumuru é um resíduo da extração do óleo de murumuru para utilização como biodiesel ou na indústria de cosméticos, não tendo valor de mercado, contudo, a logística e o valor do frete para transportar esse subproduto até onde ele foi processado para se transformar em ingrediente das rações experimentais foi elevado $(\mathrm{R} \$ 1,0 / \mathrm{kg})$ em relação ao preço do milho $(R \$ 0,56 / \mathrm{kg})$. Apesar disso, a utilização de até 15\% de torta de murumuru nas rações para caititus, substituindo $25 \%$ do milho, propiciou melhor desempenho dos animais. Tudo isso, com pouca variação em relação aos níveis de proteína, gordura e fibra em relação à ração controle, o que demonstra que este subproduto pode ser um possível substituto do milho em rações para monogástricos.

\section{CONCLUSÃO}

Os subprodutos regionais avaliados têm potencial como ingredientes e fonte de energia substitutos ao milho em grão em rações de caititus, embora aumentem os valores de fibra bruta e extrato etéreo das rações.

A inclusão de níveis de até 10\% de casca e de torta de caroço de cupuaçu (T. grandiflorum) em substituição ao milho nas rações melhora o desempenho dos caitetus (P.tajacu) alimentados com essas dietas.

A substituição do milho por diferentes níveis de torta de amêndoa de tucumã (A.aculeatum) não afetaram o peso, o ganho diário em peso, o consumo e a conversão alimentar de caititus em cativeiro, mas em função do maior custo desse ingrediente, em relação ao milho, recomenda-se utilizar apenas de 10 a 20\% deste subproduto nas rações.

As rações com inclusão de torta de murumuru foram as que tiveram valores de proteína e extrato etéreo mais próximos a ração controle, sendo sob o ponto de vista nutricional, melhor substituto para o milho como fonte de energia, sendo possível, melhorar o ganho em peso com a 
utilização de até 15\% deste subproduto na ração, substituindo 25\% da quantidade total de milho.

Todos os subprodutos testados são originários de frutos da floresta amazônica, sendo que sua utilização, além de poder reduzir o custo das rações, também apresenta-se como ecologicamente adequada.

\section{AGRADECIMENTOS}

Agradecemos ao IBAMA no Amazonas, pela cessão das instalações do CECAN e a Fundação de Amparo à Pesquisa do Estado do Amazonas (FAPEAM) pela concessão das bolsas de iniciação científica. E a dra. Maria Inêz de Oliveira-Pereira do Centro de Pesquisa em Aquacultura (CPAQ) Instituto Nacional de Pesquisas da Amazônia pelo apoio nas análises bromatológicas.

\section{REFERÊNCIAS}

ALBUQUERQUE, N.I.; DIAS, H.L.T.; GUIMARÃES, D.A.A.; LE PENDU, $Y$;; GARCIA, A.R. KAHWAGE, P.R.; CARDOSO, D.L.; SILVA, S.S.B.; SELIGMANN, I.C.A. Criação de caititus em cativeiro : sistema intensivo de produção na Amazônia Oriental. Albuquerque, N.l. (Org.), EMBRAPA, Brasília, DF: Embrapa, 2016. 108 p. Disponível em:

https://www.embrapa.br/amazoniaoriental/publicacoes.

ALBUQUERQUE, N. I.; KAHWAGE, P. R.; MOREIRA, J. A.; DIAS, H. L. T.; GUIMARÃES, D. A. Avaliação nutricional da torta de dendê (Elaeis guineensis) no desempenho de caititus (Pecari tajacu). Asian Wild Pig News, v. 12, n. 1, p. 54-61, 2013 a.

ALBUQUERQUE, N. I.; MOREIRA, J. A.; SILVA, J. V. da; MEIRELLES, C. F.; PACKER, U. I.; GUIMARÃES, D. A. Emprego do babaçu (Orbignya phalerata) como fonte energética para caititus (Pecari tajacu). Asian Wild Pig News, v. 12, n. 1, p. 61-77, 2013b

ALBUQUERQUE,N.I.;OHASHI,O.M.;GUI MARÃES,D.A.;LÊ PENDU,Y;BENIGNO. H.D.. Alternativas de sistemas de produção de caitetus (Tayassu tajacu) para a pequena agricultura na Amazônia. EMBRAPA, Belém. 2007. p.107-111

ANDRADE， P.C.M.; SILVA， R.J.A.; DUARTE， J.A.M.; CANTO, S.L;O.; COSTA, P.M.; OLIVEIRA, P.H.G. ; MONTEIRO, M.S.; BOMFIM, S.V.A.; PEREIRA, M.I.O.; PEREIRA-FILHO, M.OLIVEIRA, A.B.; RODRIGUES, W.S.; SOUSA, A.O. Manejo e Alimentação de Caitetus (Tayassu tajacu) e Queixadas (T. pecari) em cativeiro na Amazônia Central. Revista Eletrônica Manejo de Fauna Silvestre em Latinoamérica, v.2, 1-31. 2009. Disponível em: 
https://www.researchgate.net/publicati on/319003651_Manejo_e_Alimentacao de Caitetus Tayassu tajacu e Queixa das T pecari em cativeiro na Amazo nia Central

ANTUNES, A.P.; FEWSTER, R.M.; VENTICINQUE, E.M.; PERES, C.A.; LEVI, T.; ROHE, F.; SHEPARD JR., G.H. Empty forest or empty rivers? A century of comercial hunting in Amazonia. Science Advances. v.2, p.1-14. 2016.

A.O.A.C. (Association of Official Analytical (Chemists). Official Methods of Analysis of AOAC Internacional. $20^{\text {th }}$ ed. Gaithersburg.2016. 786 p.

BORGES, R.M.; MENDES, A.; NOGUEIRA, S.S.C.; BINDELLE, J. E NOGUEIRA-FILHO, S.L.G. Protein requirements of collared peccary (Pecari tajacu). Tropic Animal Health Prodution. Springer.P.1-7. 2017.

CANTO, S. L. O., M. Da S. DE ;RODRIGUES, E., C. P. DE G.; DUARTE, J. A. M.; ANDRADE, P. C. M. Consumo de produtos da fauna silvestre no Estado do Amazonas. In: Anais do IV Congreso Internacional Sobre Manejo de Fauna Silvestre en Amazonia y Latino America, Asunción,Paraguay. Anais...Asunción. p.125, 1999.

NOGUEIRA-FILHO, S.L.G.; MARTINS, K.P.M.; BORGES, R.M.; MENDES, A.; NOGUEIRA, S.S.C. E BINDELLE, J. Intake and digestion of non-traditional feedstuffs by farmed collared peccary (Mammalia, Tayassuidae). Revista Brasileira de Zootecnia, v.2, P.1-7. 2018.
Disponível

em: https://doi.org/10.1590/rbz4720170288

NOGUEIRA, S. S. C. E NOGUEIRAFILHO, S. L. G. Wildlife farming: an alternative to unsustainable hunting and deforestation in Neotropical forests? Biodiversity and Conservation. v.20. p.1385-1397. 2011. Disponível: https://doi.org/10.1007/s10531-0110047-7

NOGUEIRA-FILHO, S.L.G.; SANTOS D.O.; MENDES,A.; NOGUEIRA, S.S.C. Developing diets for collared peccary (Tayassu tajacu) from locally available food resources in Bahia, Brazil. Revista Electrónica Manejo de Fauna Silvestre en Latinoamérica. v.1, n.4, p. 1-6.2006.

NOGUEIRA-FILHO, S. L. G. The effects of increasing levels of roughage on coefficients of nutrient digestibility in the collared peccary (Tayassu tajacu). Animal Feed Science and Technology . v.120. p.:151-157. 2005. Disponível: https://doi.org/10.1016/j.anifeedsci.200 4.12.010

ROSTAGNO, H. S; ALBINO, L. F. T.; DONZELE, J. L.; GOMES, P. C.; FRREIRA, A. S.; OLIVEIRA, R. F.; LOPES, D. C. Tabelas brasileiras para aves e suínos: composição de alimentos e xigências nutricionais. Viçosa: UFV. 2000. 141p.

SANTOS, C.A.B.; NOGUEIRA-FILHO, S.L.G. Disponibilidade de frutos para caititus, Tayassu tajacu L. 1758 (Mammalia, Artiodactyla) no sul da Bahia. Revista Semiárido De Visu, v.2, n.2, p.265-273. 2012 
SANTOS, D.O.; MENDES, A.; and white-lipped peccary Tayassu NOGUEIRA, S. S.C.; NOGUEIRA FILHO, pecari (Link 1795). European Journal S. L. G. Criação comercial de caititus Wildlifel Research. v. 56, p.569-576. (Pecari tajacu): uma alternativa para o 2010.

agronegócio. Revista. Brasileira de Saúde e Produção Animal., v.10, n.1, p.1-10. 2009

SCHWARM, A.; ORTMANN, S.; RIETSCHEL, W.; KÜHNE, R.; WIBBELT, G.; CLAUSS, M. Function, size and form of the gastrointestinal tract of the collared Pecari tajacu (Linnaeus 1758)

SOUZA, H.P.G. Produção de caitetus (Tayassu tajacu, Linnaues, 1758) em dois sistemas de criação na Amazônia Central. Monografia, Zootecnia, Universidade Federal do Amazonas, Manaus, $\quad 98 \quad$ f. 2013. Disponível:http://riu.ufam.edu.br/handl e/prefix/2943 